\title{
II. DIE TROIS-ÉVÊCHÉS VOR 1552
}

Die Bezeichnung »Trois-Évêchés« ist im Französischen ein fester Begriff, der die Territorien, also den weltlichen Herrschaftsbereich der Bischöfe von Metz, Toul und Verdun sowie die drei Bischofsstädte beschreibt ${ }^{1}$. Er etablierte sich mit der französischen Einflußnahme über diese Gebiete und fand entsprechend auch in den herangezogenen Dokumenten Verwendung. Das mit $\gg$ TroisÉvêchés « bezeichnete Herrschaftsgefüge umfaßte neben den bischöflichen Territorien aber auch die Herrschaftsgebiete der Domkapitel sowie die drei Bischofsstädte, die den Status einer Reichsstadt beanspruchten. Um die einzelnen Gebiete zu lokalisieren und die komplizierte Verknüpfung der Herrschaftsrechte zwischen Städten, Bischöfen und Domkapiteln deutlich zu machen, sollen sie im folgenden kurz vorgestellt werden.

\section{Die einzelnen Herrschaftsgebiete}

Die Trois-Évêchés lagen, umschlossen von den Herzogtümern Lothringen und Bar, an der äußersten Westgrenze des Reiches. Die einzelnen Territorien waren weit verstreut, viele kleine und kleinste Gebietssprenkel, die eher eine Ansammlung von Herrschaftsrechten als ein Herrschaftsgebiet bezeichneten. Diese für das Reich insbesondere im Südwesten typische Struktur war in Lothringen besonders ausgeprägt: Die Region zwischen der Maas und den Argonnen im Westen sowie der Saar und den Vogesen im Osten bildete so, wie es der Historiker Guy Cabourdin bezeichnete, ein »mosaïque vulnérable ${ }^{2}$. Hinzu kam, daß die verstreut liegenden bischöflichen Territorien selbst wiederum in zwei Teile unterschiedlichen Charakters geteilt waren: zum einen die direkte Domäne des Bischofs, in der dieser neben der Landeshoheit auch sämtliche herrschaftlichen Rechte besaß. Zum anderen gab es Gebiete, in denen der Bischof nur noch die Landeshoheit, nicht mehr aber bestimmte Herrschaftsrechte innehatte. Insbesondere die Domkapitel und die Städte bildeten sich durch diese Konstellation zu eigenständigen politischen Faktoren innerhalb der TroisÉvêchés heraus, die auch einzeln betrachtet werden sollen.

' Vgl. Notiz im Petit Robert; Le Petit Robert. Dictionnaire alphabétique et analogique de la langue française, Paris 1991, S. 716.

${ }^{2}$ CaBourdin, Histoire de la Lorraine, Bd. 3,1, S. 5. 
Das Territorium des Bischofs von Metz war aufgrund seiner Ausdehnung, aber auch wegen der reichen Salz- und Salpetervorkommen sowie seiner strategischen Position das bedeutendste. In der Frühen Neuzeit gruppierte sich der bischöfliche Domanialbesitz um die Orte am Oberlauf der Seille, und östlich davon um das Städtchen Fribourg, sowie um Lagarde, das südlich der Seille an der Marne liegt. Ein weiterer Schwerpunkt lag am Fuße der Vogesen. Kleinere Besitzungen waren weiterhin rund um die Orte Haboudange und Albestroff südöstlich von Metz sowie um Remilly und Ancy im Umland der Stadt verstreut ${ }^{3}$.

Die Stadt Metz, bereits seit dem frühen 13. Jahrhundert faktisch unabhängig von ihren einstigen bischöflichen Stadtherren, verfügte neben dem eigentlichen Stadtgebiet uber ein bedeutendes eigenes Territorium, das sogenannte Pays Messin ${ }^{4}$. Dieser Begriff bezeichnet die in einem Umkreis von ca. $20 \mathrm{~km}$ um die Stadt liegenden Ortschaften, die meist als Lehnsherrschaften von den Mitgliedern der patrizischen Oberschicht verwaltet wurden. Mit knapp 4900 Haushalten war Metz um 1635 etwa viermal so groß wie Toul und dreimal größer als Verdun'.

Während die Stadt Metz nach einem mittelalterlichen Sprichwort als »die Reiche « bezeichnet wurde, hatte sich für Toul der Beiname "die Heilige« eingebürgert. Der Ausdruck weist bereits auf das Sozialgefüge von Toul in der Frühen Neuzeit hin. Obwohl verkehrsgünstig an einer Moselschleife im Herzen Lothringens gelegen, hatte die Stadt im Laufe des 16. Jahrhunderts durch den Aufstieg der nahegelegenen Herzogsresidenz Nancy erheblich an Bevöl-

${ }^{3}$ Eine detaillierte Aufstellung der einzelnen Herrschaftsbereiche des Bischofs, ihrer Hauptorte und dazugehörigen Dorfer sowie der wichtigsten Lehen hat die Autorin in ihrer Magisterarbeit angefertigt: Christine PETRY, Das Gerichtswesen in Hochstift und Bistum Metz in der Frühen Neuzeit, Magisterarbeit (masch.) Universität Trier 1997, S. 20-24. Im Gegensatz zu den Domkapiteln von Toul und Verdun schien das von Metz nicht liber größere Besitzungen zu verfügen.

${ }^{4}$ Zur Stadtgeschichte von Metz im Mittelalter sei auf drei wichtige Studien hingewiesen, die im Rahmen des Teilprojektes »Städte zwischen Rhein und Maas im Herrschafts- und Sozialgefüge während des hohen und späten Mittelalters im Vergleich« des Trierer Sonderforschungsbereiches $235 » Z$ wischen Maas und Rhein entstanden sind: PUNDT, Metz und Trier; Margit MưLLER, Am Schnittpunkt von Stadt und Land. Die Benediktinerabtei St. Amulf zu Metz im hohen und späten Mittelalter, Trier 1993 (Trierer Historische Forschungen, 21) sowie Gisela MiNN, Kathedralstadt und Benediktinerkloster. Die Abtei St. Vinzenz und die Stadt Metz im Mittelalter, Trier 2002 (Trierer Historische Forschungen, 45). Den Mitarbeitern des Städteprojekts, insbesondere dem Projektleiter Herrn Prof. Haverkamp und Frau Dr. Minn danke ich fur Hinweise.

${ }^{5}$ Vgl. zu Metz AMAE, CP Lorr. 11, fol. 18-25 (exakt werden hier 4873 Haushalte genannt); zu Toul Daulnoy, PILlEmENT (Hg.), Mémoires de Jean du Pasquier, procureur syndic de la cité de Toul, Toul 1878, S. 7 (für das Jahr 1634 werden 1284 Haushalte genannt); zu Verdun A.C. Verdun CC 22 (eine Steuerliste von 1614, sie listet 1617 Haushalte auf). 
kerung und Wirtschaftskraft eingebüßt - zurück blieben allein die Mönche und Stiftsherren der zahlreichen kirchlichen Institutionen, die Toul tatsächlich als wheilige« Stadt erscheinen ließen. Der bischöfliche Einflußbereich erstreckte sich in Toul, anders als in Metz, auch auf das Stadtgebiet. Das Territorium teilte sich in drei Gebietsteile, die stark verstreut um die Hauptorte Blénod-lèsToul im Süden der Stadt, Brixey-aux-Chanoines an der Maas sowie Liverdun im Moseltal lagen ${ }^{6}$. Anders als im Hochstift Metz besa $§$ das reiche und mächtige Domkapitel von Toul auch eigene Herrschaften, die im Weinbaugebiet nördlich der Stadt sowie weit südlich um Vicherey gelegen waren?

Während die Einflußbereiche der Bischöfe von Metz und insbesondere von Toul sehr stark zersplittert waren, verfügte der Bischof von Verdun über ein relativ geschlossenes Territorium, das sich im Umland der Stadt befand. Es war in sechs Verwaltungseinheiten, sogenannte prévôtes unterteilt ${ }^{8}$. Im selben Bereich besaß auch das Domkapitel Land, sieben jeweils sehr kleine Herrschaften?.

Sowohl die drei Hochstifte als auch die dazugehörigen Städte als Reichsterritorien bzw. -städte hatten Sitz und Stimme im Reichstag und mußten Beiträge zur Reichsmatrikel leisten ${ }^{10}$. Sie waren dem oberrheinischen Kreis zugeordnet. Tatsächlich jedoch war die Reichsstandschaft zu diesem Zeitpunkt insbesondere bei den Städten noch nicht endgültig festgelegt ${ }^{1}$, so daß bei den Reichstagen sowie bei der Korrespondenz mit Institutionen und Funktionsträgern des Reiches nicht immer alle drei Städte als Reichsstädte auftraten, dafür aber beispielsweise die Domkapitel von Toul und Verdun quasi als Reichsstände angesprochen wurden.

Trotz ihrer Reichszugehörigkeit wurde in den Trois-Évêchés von jeher überwiegend französisch gesprochen. Lediglich ein kleinerer Teil im Osten

${ }^{6}$ CABourdin, Histoire de la Lorraine, Bd. 3,1, S. 6.

${ }^{7}$ Vgl. die Karte bei Guy CABOURDIN, Terre et hommes en Lorraine 1550-1635, 2 Bde., Nancy 1977, hier Bd. 1, S. 11.

${ }^{8}$ Dies waren die Hauptorte Fresnes-en-Woëvre, Mangiennes, Charny, Tilly, Dieppe und Hattonchâtel, wo der Bischof bis 1546 auch seinen Verwaltungssitz hatte. Vgl. Jean SCHNEIDER, La cité de Verdun à la veille du voyage d'Austrasie, in: Annales de l'Est 3 (1952) S. 327-348, hier S. 338.

${ }^{9}$ Vgl. die Aufzählung in A.D. Meuse 11 F 15, zw. fol. 16 und 17.

${ }^{10}$ Die Reichsmatrikel von 1521 nennt die Bischöfe von Metz, Toul und Verdun bei den geistlichen Reichsständen, die entsprechenden Städte bei den Reichsstädten. Vgl.: J. G. SCHMAUSS, H. C. SENCKENBERG (Hg.), Neue und vollständige Sammlung der Reichsabschiede, 4 Bde., Frankfurt a. M. 1747, hier Bd. 2, S. 217-221. Zur Bedeutung der Matrikel von 1521 vgl. Helmut NeuHaus, Das Reich in der frühen Neuzeit, München 1997 (Enzyklopädie deutscher Geschichte, 42), S. 20.

"Vgl. dazu NeuHauS, Reich, S. 19-21, 34. 
des Hochstifts Metz war deutschsprachig ${ }^{12}$. Das französischsprachige lothringische Herzogshaus, das die Bistümer und Hochstifte weitgehend durch seine Familienangehörigen kontrollierte, schien zudem seit Beginn des 16. Jahrhunderts darauf hingearbeitet zu haben, das Französische als Amtssprache weiter auszubreiten ${ }^{13}$. Wie in Kapitel IV gezeigt werden soll, erschwerte der Sprachunterschied die Beziehungen zum Reich und sollte umgekehrt die Eingliederung der Trois-Évêchés in das Königreich Frankreich erleichtern.

Die Verwaltung der einzelnen Städte und Territorien war weitgehend ähnlich organisiert. Sie soll im folgenden vor allem am Beispiel der Verwaltung im Hochstift und der Stadt Metz kurz vorgestellt werden: Das höchste Amt in der Verwaltung der Hochstifte hatte jeweils der sogenannte bailli, eine Art Statthalter, inne. Diese Institution war im gesamten französischen Raum verbreitet $^{14}$. In einer Beschreibung des Hochstifts Metz von 1607 heißt es zum bailli: $[i l]$ gouverne seul le dit évesche ${ }^{15}$. Zuvorderst waren es militärische Aufgaben, mit denen der bailli befaßt war ${ }^{16}$. Darüber hinaus war er Vorsitzender des obersten bischöflichen Gerichtes, der bailliage, und somit chef [...] de la Justice \& de la Police ${ }^{17}$. Das Amt des bailli wurde mit einem Angehörigen des Adels besetzt und war - auch hier gibt es Parallelen zum Königreich

${ }^{12}$ Vgl. hierzu die Karte bei Hans WITTE, Zur Geschichte des Deutschtums in Lothringen. Die Ausdehnung des deutschen Sprachgebietes im Metzer Bistume, in: Jahrbuch der Gesellschaft für lothringische Geschichte und Altertumskunde 2 (1890) S. 231-300 [Beilage zum Band].

${ }^{13}$ So ordnete 1505, zwanzig Jahre nach dem Tod des letzten deutschsprachigen Bischofs von Metz, das Domkapitel von Metz, das die Regierung für den minderjährigen Bischof Jean de Lorraine führte, an, Berufungen zu Ämtern im Bistum in Zukunft nur noch in französischer Sprache auszustellen. Spätestens seit dieser Zeit war das Französische also Amts- und damit auch Gerichtssprache. Latein scheint in der weltlichen Verwaltung des Hochstifts schon seit dem späten Mittelalter keine Rolle mehr gespielt zu haben. Gut ablesen läßt sich die sprachliche Entwicklung anhand der Sprache in den Urkunden und Dokumenten aus der bischöflichen Kanzlei z.B. an den Kapitularien der Metzer Bischöfe des späten Mittelalters wie A.D. Moselle, $\mathrm{G} 5$ bis $\mathrm{G}$ 14, in denen Latein immer seltener wird. Auch in der geistlichen Verwaltung gewann das Französische zunehmend an Bedeutung: Während für Bischof Henri de Lorraine um 1500 noch ein lateinisches Traktat abgefaßt wurde, das die Aufgaben der geistlichen Gerichtsbarkeit erläuterte, wurde diese etwa 100 Jahre später durch Anne de Givry in einer französischsprachigen Ordonnanz reformiert (vgl. A.D. Moselle, G 231 und $25 \mathrm{~J}$ 126).

${ }^{14}$ Vgl. MIECK, Die Entstehung des modernen Frankreich, S. 175f.; MOUSNIER, Institutions, S. 264f., Julius R. RUFF, Crime, justice and public order in Old Regime France. The Sénéchausées of Libourne and Bazas 1696-1789, London u.a. 1984, S. 28.

${ }^{15}$ Denkschrift von 1607, abgedruckt in: HAMMERSTEIN, Der Metzer Bischof, hier S. 162.

${ }^{16} \mathrm{Ihm}$ oblag die Verwaltung aller militärischen Angelegenheiten und der Unterhalt der Festungen, aber auch die Sicherstellung des Unterhalts und der Unterbringung der Armee, sowie die Aushebung von Truppen und die Anschaffung neuen Kriegsgeräts. Vgl. die Denkschrift von 1607, in: HAMMERSTEIN, Der Metzer Bischof, S. 162.

${ }^{17}$ Denkschrift von 1635, A.D. Moselle, G 24 (22), fol. 1r. 
Frankreich - in den Trois-Évêchés käuflich ${ }^{18}$. Die Zugehörigkeit eines Großteils der Amtsträger zum lothringischen Hochadel ${ }^{19}$ führte dazu, daß die baillis meist am herzoglichen Hof in Nancy oder in ihren Adelsherrschaften residierten und in ihren Amtssitzen nur selten anzutreffen waren ${ }^{20}$. Die täglichen Aufgaben in Rechtsprechung und Verwaltung nahm eine Art Stellvertreter, der lieutenant général, wahr. Er mußte im Gegensatz zum bailli Recht studiert haben. Auch residierte er vor Ort und wurde insbesondere im Hochstift Metz zur eigentlichen Hauptfigur in der bischöflichen Regierung ${ }^{21}$.

Die zentrale Verwaltung der Finanzen oblag im Hochstift Metz einer Art Geheimem Rat. Mit dem bailli an der Spitze bestand er aus den wichtigsten Amtsträgern des Hochstiftes ${ }^{22}$. Daneben hatte der Rat offenbar aber auch eine Kontrollfunktion über die übrigen bischöflichen Beamten: il entend les comptes et les plainctes des subjectz contre les officiers et en juge ${ }^{23}$. Er übernahm während der Abwesenheit des Bischofs dessen gesamte hoheitliche Aufgaben. Da die Metzer Bischöfe des 16. und frühen 17. Jahrhunderts nur selten in ihrem Bistum anzutreffen waren, war der Geheime Rat so zur eigentlichen Regierung des Hochstiftes geworden.

Dem bailli unterstellt waren die sogenannten maires in den Städten und Hauptorten der Territorien. Sie waren zuständig für die Verteidigung, la garde des portes et murailles ${ }^{24}$. In Toul nahm der maire darüber hinaus auch Polizeiaufgaben $w a h r^{25}$. Die Kastellane (châtelains oder prévôts) hatten eine ähnliche

${ }^{18}$ Die Denkschrift von 1635 nennt für das Hochstift Metz in den Jahren vor 1633 die Kaufsumme von 4000 francs barrois. A.D. Moselle, G 24 (22), fol. 2 v.

${ }^{19}$ So stammte Jean des Porcelets de Maillane aus einer alteingesessenen Familie des Herzogtums - er war vor und nach seiner Amtszeit als bischöflicher bailli (1591 bis ca. 1603) in den höchsten herzoglichen Hofämtern tätig (vgl. Émile DUVERNOY, Jean des Porcelets de Maillane, Bailli de l'évêché de Metz, in: Les Cahiers Lorrains 8 (1929) S. 21-23). Auch Jean d'Haussonville, bischöflicher bailli in der ersten Hälfte des 16. Jahrhunderts, hatte neben seinem bischöflichen Amt noch den Titel des Seneschalls des Herzogs von Lothringen inne (vgl. A.D. Moselle, B 10852, fol. lr).

${ }^{20}$ Émile DUVERNOY, Alphonse de Rambervillers et le bailliage de Vic aux XVI et XVII siècles, in: Mémoires de la société d'archéologie lorraine 58 (1908) S. 279-370, hier S. 311.

${ }^{21}$ Dies lag nicht zuletzt an den Fähigkeiten der Amtsinhaber im 16. Jahrhundert, vgl. z. B. die beiden Vertreter der Familie Rambervillers, Euchaire und sein Neffe Alphonse de Rambervillers, von denen Biographien vorliegen: DUVERNOY, Alphonse de Rambervillers, und Henri TRIBOUT DE MOREMBERT, Euchaire de Rambervillers, lieutenant général du bailliage de Vic, in: Annales de l'est 25 (1975) S. 229-236.

${ }^{22}$ Martin MEURISSE, Histoire des Esveques de l'église de Metz, Metz 1634, S. 30: Dem lieutenant, dem procureur, dem Schatzmeister, und evtl. dem Suffragan des Bistums, wobei die Ämter des procureur, des Kanzlers und des Schatzmeisters erst im Laufe des 16. Jahrhunderts geschaffen wurden, vgl. dazu DUVERNOY, Alphonse de Rambervillers, S. 291.

${ }^{23}$ Denkschrift von 1607, in: HAMMERSTEIN, Der Metzer Bischof, S. 162.

${ }^{24}$ Denkschrift von 1607 , ibid.

${ }^{25}$ Er vollstreckte beispielsweise auch Zwangspfändungen vgl. AMAE, CP Lorr. 10, fol. 178. 
Aufgabe in der Überwachung der Befestigungen und Burgen der Hochstifte ${ }^{26}$. Sie waren die Vorsteher der einzelnen Verwaltungseinheiten der Territorien, und für die Finanz- sowie die Forstverwaltung zuständig. Zudem hatten sie Aufgaben in der Rechtssprechung inne ${ }^{27}$. Als Vertreter der Herrschaft vor Ort wurden sie von den baillis oder vom Geheimen Rat ernannt ${ }^{28}$.

Die nach den Bischöfen wichtigsten Akteure, sowohl im geistlichen wie im weltlichen Bereich, waren die Domkapitel. Diese hatten nicht nur das Recht zur Bischofswahl, sondern übernahmen auch während einer Sedisvakanz oder der Minderjährigkeit eines designierten Bischofs die geistliche wie weltliche Regierungsgewalt in Bistum und Hochstift. Obwohl die Domkapitel ihr Recht zur Bischofswahl nur selten dazu nutzten, eine bestimmende Stellung in Bistum und Hochstift zu erlangen ${ }^{29}$, gab es also durchaus Möglichkeiten, politischen oder kirchenpolitischen Einfluß zu nehmen. Vor allem die Vormundschaftsregierungen für minderjährige Bischofsanwärter boten den Domherren die Möglichkeit, konkret Macht auszuüben ${ }^{30}$. Hinzu kamen vor allem in Toul und Verdun noch ein beträchtlicher Territorialbesitz, der zwar lose unter der Oberverwaltung und insbesondere Gerichtsbarkeit des bischöflichen bailli zu stehen schien, der aber den Kapiteln dennoch eine weitgehende wirtschaftliche Selbständigkeit garantierte.

Über die Situation und Organisation der drei Stadtgemeinden von Metz, Toul und Verdun sind wir wesentlich besser informiert als über die bischöflichen Territorien. Ihre verfassungsrechtliche Stellung scheint allerdings weitgehend ungeklärt: Alle drei Städte beanspruchten für sich den Status einer

\footnotetext{
${ }^{26}$ Denkschrift von 1607, in: HAMMERSTEIN, Der Metzer Bischof, S. 162.

${ }^{27}$ PROST, Albestroff, S. 49f.

${ }^{28}$ So in Toul, vgl. AMAE, CP Lorr. 10, fol. 178.

${ }^{29}$ Dies war vor allem darin begründet, daß die Bischofswahlen im frühneuzeitlichen Lothringen alles andere als "frei« verliefen. Anstatt sich von eigenen kirchlichen oder auch machtpolitischen Erwägungen leiten lassen zu können, mußten sich die Domkapitel meist äußerem Druck von seiten des Herzogs von Lothringen beugen. Vgl. beispielsweise zu Verdun Alain GIRARDOT, in: DERS. (Hg.), Histoire de Verdun, Toulouse 1982, S. 118-120. Zu Toul: PIMODAN, Réunion, S. XIX.

${ }^{30}$ Ein Beispiel hierfür ist das Hochstift Metz, in dem 1505-1518 (für Jean de Lorraine) und 1578-1585 (für Charles de Lorraine, mit dem Bischof von Verdun geteilt) sowie noch einmal 1612-1621 (furr Henri de Bourbon) das Domkapitel als Vormundschaftsregierung die Geschicke bestimmte. Insgesamt wurde das Hochstift Metz also innerhalb der 133 Jahre zwischen 1500 und 1633 dreiBig Jahre lang von den Domherren regiert. Vgl. Robert FoLZ, Le concordat germanique et l'élection des évêques de Metz (1450-1668), in: Annuaire de la société d'histoire et archéologie de la Lorraine 40 (1931) S. 157-305, hier S. 84, 109f. und 129. Auch in Toul beanspruchte das Domkapitel weitgehende Rechte bei einer Vakanz des Bischofsstuhles. Noch 1636, also bereits zu einem Zeitpunkt, an dem zahlreiche Herrschaftsrechte an den König übergegangen waren, versuchte es seine Rechte zur Ernennung der städtischen Beamten bei Sedisvakanz gegen die königlichen Amtsträger in der Stadt durch eine Klage vor dem conseil du roi durchzusetzen. Vgl. BnF, N.a.fr. 22617, fol. 52-55.
} 
freien Reichsstadt, jedoch verfügte lediglich in Metz der Bischof tatsächlich liber keinen weltlichen Einfluß mehr. Gestützt auf das reiche und ausgedehnte Umland, das sogenannte Pays Messin, konnte die Stadt eigene politische Ziele verfolgen. Daß die Stadtgemeinde Metz, die sich im Mittelalter so erfolgreich gegen seinen bischöflichen Stadtherren behauptet hatte, dennoch 1552 widerstandslos vor dem französischen König und dem Bischof zusammenbrach, wird verständlich, wenn man die Lage in den Jahren davor betrachtet. Hierbei lassen sich durchaus auch Parallelen zu Toul und Verdun ziehen, auf die später eingegangen werden soll, und die weitgehend mit ähnlichen strukturellen Problemen zu kämpfen hatten.

Der sprichwörtliche Reichtum von Metz im Mittelalter ${ }^{31}$ war zu Beginn der Frühen Neuzeit nicht mehr zu erkennen ${ }^{32}$. Auch die wirtschaftliche Situation der beiden anderen Kathedralstädte war kaum besser: Verdun erlebte nach der hochmittelalterlichen Blüte ebenfalls einen dramatischen wirtschaftlichen Niedergang, der parallel mit dem Aufstieg kleiner Städte im Umland einherging $^{33}$. Toul war als Weinproduzent und -handelsplatz fast völlig von der Marktlage eines einzigen Produktes abhängig, was ebenfalls zu einer prekären wirtschaftlichen Situation führte ${ }^{34}$. In allen drei Städten trug die ständige Bedrohung durch Auseinandersetzungen mit den Truppen benachbarter Territorien und Raubrittern noch weiter zu einem Gefühl des Niedergangs bei.

Die innere Situation der Städte war durch ihr starres soziales Gefüge geprägt. Metz war beispielsweise seit dem 13. Jahrhundert in Form einer oligarchischen Republik organisiert ${ }^{35}$, die von den Mitgliedern der paraiges regiert wurde, einzelnen Patrizierfamilien, die sich zu einer hermetisch abgeschlossenen Kaste entwickelt hatten und keinerlei Aufstieg duldeten. Diese Abschottung gegen das Bürgertum und die daraus resultierende Heiratspolitik war den paraiges zum Verhängnis geworden: Die Ehen zwischen nahen Verwandten blieben häufig kinderlos ${ }^{36}$ und es fanden sich zunehmend nicht mehr genug

\footnotetext{
${ }^{31}$ Von Reichtum und Lebensqualität dieser Stadt zeugt auch das damals kolportierte Sprichwort Si Francfort était mien, je le dépenserais à Metz, vgl. Léon BoUR, Histoire de Metz, Metz 1989, S. 88.

${ }^{32}$ Pestepidemien, eine Verlagerung der Handelswege, und vor allem ständige kriegerische Auseinandersetzungen mit dem Herzogtum sowie mit den Truppen umherstreifender Raubritter hatten die Stadt wirtschaftlich und politisch geschwächt. Vgl. Alain GIRARDOT, in: François-Yves LE MOIGNE (Hg.), Histoire de Metz, Metz 1986, S. 149-157.

${ }^{33} \mathrm{Vgl}$. hierzu HIRSCHMANN, Verdun, Bd. 2, S. 721-729, 778-782. Auch hier wirkte sich die Verlagerung der Handelsstròme aus, die die Stadt vom Fernhandelszentrum zum »Modeste marché rural« gemacht hatten. Vgl. ibid. und ScHNEIDER, Cité de Verdun, S. 331.

${ }^{34} \mathrm{Vgl}$. dazu BIESEL, Hexenjustiz, S. 79-80, und Claude KUNEGEL, Toul au XVI ${ }^{c}$ siècle. Problème des prix et gestion financière, in: Annales de l'est 2 (1952) S. 307-326.

${ }^{35}$ ZELLER, Réunion, Bd. 1, S. 181.

${ }^{36}$ So zählte man 1537 statt der etwa 330 Familienoberhäupter des 15 . Jahrhunderts nur noch 25 Männer. Vgl. BouR, Histoire de Metz, S. 90.
} 
erwachsene Männer, um die zahlreichen Ämter der ursprünglich wohldurchdachten städtischen Verwaltung besetzen zu können. Der Mangel an amtsfähigen Angehörigen der Patrizierschicht trieb in Metz seltsame Blüten, die die Funktionsfähigkeit der städtischen Regierung deutlich einschränkten: So war der Rat, nach der ursprünglichen Anzahl seiner Mitglieder die »Dreizehn« (Treize) genannt, zu Beginn des 16. Jahrhunderts meist nur noch mit acht oder neun, später gar nur noch mit vier Männern besetz ${ }^{37}$. Kinder mußten die Lücken schließen: Männliche Patrizier wurden schon mit zwölf Jahren zu Schöffen ernannt, und für das höchste städtische Amt des Schöffenmeisters mußte man nur noch sechzehn Jahre alt sein ${ }^{38}$.

In Verdun kontrollierten ebenfalls drei große Patrizierfamilien, die den Rat der Stadt bildeten und lignages genannt wurden, fast die gesamte Politik ${ }^{39}$. Aber anders als in Metz hatte sich der Bischof in Verdun das Nominationsrecht für städtische Ämter bewahrt, auch wenn diese ausschließlich an lignages-Angehörige übertragen werden durften ${ }^{40}$. Genau wie in Metz hatte sich das städtische Patriziat von Verdun im Laufe des 15. Jahrhunderts dramatisch verringert ${ }^{41}$. Zusätzlich gefährdet war die innere Stabilität durch die immer offener zu Tage tretende Feindseligkeit eines Großteils der Stadtbevölkerung gegenüber der mächtigen Oberschicht, die - allerdings in weniger deutlicher Form - auch in Metz zu beobachten war ${ }^{42}$.

Lediglich in Toul scheint die Abschottung der städtischen Oberschicht weniger stark gewesen zu sein: Zwar wurden auch hier die städtischen Funktionsträger aus den Reihen der wohlhabenden Bürger gewählt und dann vom Bischof ernannt, eine den paraiges oder lignages vergleichbare Schicht ist jedoch nicht bekannt. Im Gegenteil schien in der Stadt nur ein Status für alle Bewohner zu existieren, der dem Adelsstand, zumindest wurde dies so propagiert, nahezu gleichkam ${ }^{43}$.

In allen drei Städten war die politische Stimmung am Anfang des 16. Jahrhunderts deutlich zuungunsten des Reiches gekippt. Vor allem die Reichssteu-

\footnotetext{
${ }^{37}$ Eine Aufzählung der Mitglieder der paraiges um die Wende zum 16. Jahrhundert, sowie die Namen der Mitglieder des Rates der Dreizehn bis 1519 bei FRANÇOIS, TABOUILlot, Histoire générale, Bd. 4, S. 529-536.

${ }^{38}$ Bour, Histoire de Metz, S. 95.

${ }^{39}$ Eine Liste der Familien, die um 1550 zu den drei lignages gehörten, findet sich in BnF, N.a.fr. 22625, fol. 47-50.

${ }^{40}$ SCHNEIDER, Cité de Verdun, S. 332-335.

${ }^{41}$ Ibid. S. 335.

${ }^{42}$ Ibid. S. 336

${ }^{43}$ CABOuRdiN, Terre et hommes, Bd. 1, S. 159, Lucie RouX, L'histoire municipale de Toul de l'occupation française à l'annexion (1552-1648), in: Position des Thèses de l'École des chartes (1956) S. 77-82, hier S. 77.
} 
ern wurden als zu hoch kritisiert ${ }^{44}$. Hingegen waren die Beziehungen von Toul und Verdun zum Herzogtum Lothringen und auch zu Frankreich relativ gut schon wegen der Erleichterung des Handels in den zersplitterten Territorien war man stets um einen Ausgleich mit den benachbarten Herrschaftsgebieten bemuiht.

In Metz hingegen waren die Beziehungen zum Herzogtum Lothringen deutlich kühler, denn die zahlreichen militärischen Auseinandersetzungen mit dem Herzog hatten die alte Feindschaft immer wieder genährt. Der französische König aber hatte auch in Metz zahlreiche Sympathisanten - vor allem unter den Protestanten ${ }^{45}$.

Die Ständeversammlungen (états) der bischöflichen Territorien und auch der drei Städte sollten bei den Ereignissen in den Jahren nach 1552 zunehmend einen wichtigen politischen Faktor darstellen. Sie waren aus Vertretern des Adels (in den Städten das Patriziat), der Geistlichkeit und des sogenannten Dritten Standes (dies waren in den Hochstiften beispielsweise die Vertreter der Städte, Dörfer und Gemeinden, in den Städten alle Bewohner mit Bürgerrecht $^{46}$ ) zusammengesetzt. Sie wurden in unregelmäßigen Abständen einberu$\mathrm{fen}^{47}$. Die genaue Funktion der Ständeversammlungen ist schwierig zu erschließen. Lediglich für das Hochstift Metz gibt es hier einige Anhaltspunk-

$44 \mathrm{Zu}$ Verdun umfassend: Charles AIMOND, Les relations de la France et du Verdunnois de 1270-1552, Paris 1910, ND Genf 1975, S. 360-432, zu Metz ZelleR, Réunion, Bd. 1, S. 207-283; zu Toul PimOdan, Réunion, S. $11 \mathrm{f}$.

${ }^{45}$ Die Zustände und Stimmungen in Metz sind im ersten Band von ZELLER, Réunion, ausführlich geschildert. Da dieser Band sich fast ausschließlich mit den oben geschilderten Fragen befaßt, eruibrigt sich eine Seitenangabe.

${ }_{46}$ A.D. Moselle, G 24 (22), fol. $1 \mathrm{r}$.

${ }^{47}$ Hierbei scheint es, daß sich die Ständeversammlungen insbesondere in den Städten erst unter dem Einfluß der Bischöfe aus dem Umfeld des lothringischen Herzogshauses zu Beginn des 16. Jahrhunderts durchgesetzt haben: Während für Toul in der ersten Hälfte des 16. Jahrhunderts gar keine dieser Versammlungen gefunden werden konnten, lassen sich im Hochstift Metz vor 1552 nur zwei, im gesamten Untersuchungszeitraum bis 1648 nur 12 Ständetage nachweisen. Zu diesem Zweck wurde das Register oder Inventar des bischöflichen Archivs von 1767 (A.D. Moselle, G 37) ausgewertet. In der Stadt Metz sind Ständeversammlungen für die erste Hälfte des 16. Jahrhunderts belegt. Hier waren solche Versammlungen vor allem bei Kriegsbedrohung und im Falle von Steuerforderungen des Reiches, wie 1512 und 1534, einberufen worden. Die Abgeordneten des dritten Standes wurden hierbei von allen Bürgern einer Pfarrei gewählt, vgl. dazu ZELLER, Réunion, S. 183f. In Verdun ist nach Aimond die erste Ständeversammlung im Jahr 1528 belegt, zwei weitere fanden in den Jahren 1533 und 1538, in Zusammenhang mit den Neutralitätsverhandlungen des Hochstifts im Konflikt zwischen Karl V. und Franz I. statt. Vgl. AlMOND, Rélations, S. 365, Anm. 5. 
te: Wichtigste Aufgabe war sicherlich die Steuerbewilligung ${ }^{48}$. Daneben waren die Stände an der Gesetzgebung beteiligt ${ }^{49}$. Weiterhin traten Versammlungen wohl auch aus anderen Anlässen zusammen. Feindliche Truppeneinfälle und anstehende Reichstage sind als solche Anlässe überliefert ${ }^{50}$. Eine beträchtliche Zahl an Vasallen erschien allerdings auch gar nicht zu diesen seltenen Versammlungen - wohl auch wegen der zum Teil großen Entfernungen ${ }^{51}$. Für die vorliegende Untersuchung sind insbesondere die städtischen Ständeversammlungen der ersten Hälfte des 17. Jahrhunderts von Interesse. Hierbei handelt es sich jedoch nicht um Beratungen zur Steuerbewilligung, sondern um Versammlungen, auf denen explizit politische Fragen behandelt wurden, die die ganze Stadt betrafen.

\section{Der geistliche Einflußbereich der Bischöfe}

Zusammen genommen deckten die drei Diözesen von Metz, Toul und Verdun beinahe ganz Lothringen ab, waren also sehr viel größer als die Territorien ihrer Bischöfe. Obwohl auch die drei Diözesen stets in einem Atemzug genannt wurden, waren sie in ihrer Größe und Bedeutung recht unterschiedlich.

${ }^{48}$ Nach der Denkschrift von 1635 (A.D. Moselle, G 24 (22), fol. 1r) wird diese als einzige Aufgabe der Stände aufgefuihrt.

${ }^{49}$ Das Ausmaß ihrer Beteiligung bei der Gesetzgebung geht aus den Quellen nicht klar hervor. Sicher ist, daß das Zivilrecht (coutume) des Hochstifts Metz sowie eine Regelung über die Anzahl der Gerichtstage beim Adelsgericht vom Bischof von Metz in Zusammenwirkung mit den Ständen beschlossen wurden. Die Redaktion der coutume wurde von einer Ständeversammlung vorgeschlagen und die fertige Fassung muBte den Ständen vorgelegt werden (vgl. A.D. Moselle, B 24 (4), v.a. fol. 2r, 4r). Auch eine Denkschrift zur Verwaltung des Territoriums aus dem Jahr 1607 spricht davon, daB der Bischof von Metz die Gesetze avec l'advis des etaz beschlossen hatte. Auf beide Beschlüsse wird noch näher einzugehen sein. Vgl. A.D. Moselle, 2 F 14 ; Denkschrift von 1607, in: HAMMERSTEIN, Der Metzer Bischof, S. 161. Kleinere Einzelfallregelungen wie die in den Sentenzen der bailliage des Metzer Hochstifts in Vic registrierten ordonnances wurden jedoch ohne Beteiligung der Stände erlassen. Dies erschließt sich zum einen aus der Seltenheit solcher Ständetage, zum anderen aus dem Wortlaut der Ordonnanzen selbst (z.B. Ordonnanz vom 25.2.1579; A.D. MeurtheMos., BJ 1458, fol. 22v).

${ }^{\text {so }}$ Aus dem Inventar von 1767, A.D. Moselle, G 37, fol. 209.

${ }^{51}$ A.D. Moselle, G 24-4, fol. 2r: come aussy il apparoissoit par la lecture du Ruolle \& denombremens des appellés qu'il y avoit bon nombre des absens \& defaillants... Vgl. auch A.D. Moselle, G 37, dort v.a. die Entschuldigungen auf fol. 209. 
Das Bistum Metz war im 16. Jahrhundert mit mehr als 500 Pfarreien $^{52}$ das größte und wichtigste der Trois-Évêchés. Die größte politische Bedeutung entwickelte jedoch in der Zeit der französischen Einflußnahme das Bistum Toul, da sein ebenfalls sehr ausgedehntes Gebiet in weiten Teilen deckungsgleich mit dem zunächst nicht unter französischer Kontrolle stehenden Herzogtum Lothringen war. Die Diözese Verdun war als kleinste auf ein Gebiet im Umkreis von ca. $30 \mathrm{~km}$ rund um die Bischofsstadt beschränkt.

Kirchenrechtlich unterstanden alle drei als Suffraganbistümer dem Trierer Erzbischof und dessen Jurisdiktion. Doch schien sich das Band zu Trier schon relativ früh gelockert zu haben ${ }^{53}$. Die Zugehörigkeit der drei Bistümer zur Reichskirche zeigte sich somit weniger am ausgedehnten Kontakt mit dem Metropolitanbistum als vielmehr bei der Bischofswahl: Genau wie in Trier wurden auch in Metz, Toul und Verdun die Bischöfe in kanonischer Wahl von den Domkapiteln gewählt und vom Papst bestätigt, während in der französischen Kirche die Rechte von Papst und Domkapiteln weitgehend beschränkt waren $^{54}$. Faktisch war die "freie« Wahl der Kanoniker in den drei lothringischen Bischofsstädten jedoch nur Fassade. Denn die Bischofssitze lagen fest in der Hand von Mitgliedern des lothringischen Herzogshauses ${ }^{55}$. Im Herzogtum erhoffte man sich durch diese Politik vor allem eine stärkere Einflußnahme auf die bischöflichen Territorien, aber auch - in Ermangelung eines »eigenen « Bistums z.B. in Nancy - eine bessere Einwirkung auf die geistlichen Belange in den Bistümern, deren Bewohner ja gleichzeitig Untertanen des Herzogs waren ${ }^{56}$. Auch finanzielle Gründe standen hinter dieser Politik. Das Herzogtum Lothringen profitierte im 16. Jahrhundert sehr davon, daß die Bischöfe von Metz, Toul und Verdun immer wieder Teile ihrer Territorien an den Herzog verlehnten oder verpfändeten. So trug beispielsweise die Gewäh-

${ }^{52}$ Zahl zur Zeit des Bischofs Jean de Lorraine. Vgl. Henri Tribout DE MOREMBERT, Le diocèse de Metz, Paris 1970, S. 106.

${ }^{53}$ Es wäre wünschenswert, die Beziehungen zwischen Trier und seinen Suffraganbistümern einmal einer genaueren Analyse zu unterziehen, jedoch kann dies im Rahmen der vorliegenden Arbeit nicht geleistet werden. Eine kursorische Sichtung der Archivbestände in Koblenz, Trier und Metz hatte jedoch zum Ergebnis, daß der Austausch und die Korrespondenz zwischen Trier und den drei lothringischen Diözesen nicht sehr umfangreich waren. Vgl. den Bestand 7, 9 und 10 des Landeshauptarchivs Koblenz sowie die Akten vor allem der Abteilung 6 des Bistumsarchivs Trier.

${ }^{54}$ Vor allem seit Abschluß des Konkordates von 1516 war die Besetzung von Bischofs- und Abtsstellen im Königreich Frankreich allein Sache des Königs. Vgl. hierzu und zum Gallikanismus allgemein: Hans Erich FEINE, Kirchliche Rechtsgeschichte. Die katholische Kirche, 5. Aufl., Köln, Wien 1972, S. 486f.

${ }^{55}$ CHÂtelliER, Lothringen, S. 101, CABOURDiN, Histoire de la Lorraine, Bd. 3,1, S. $21 \mathrm{f}$.

${ }^{56}$ Michel PERNOT, La Maison de Lorraine dans l'église de l'Empire, in: Jean-Paul BLED u.a. (Hg.), Les Habsbourg et la Lorraine, Nancy 1988, S. 67-80, hier S. 67. 
rung von Nutzungsrechten an den Salinen des Bischofs von Metz deutlich zur Wirtschaftskraft des Herzogtums bei ${ }^{57}$.

Die solcherart gewählten Bischöfe waren in der Regel wenig an geistlichen Belangen interessiert und hatten, wenn überhaupt, nur die niederen Weihen empfangen. Sie hielten sich meist am Hof in Nancy auf. Ihre pastoralen Aufgaben wurden von Weihbischöfen wahrgenommen ${ }^{58}$.

Im Laufe des 16. Jahrhunderts hatte die Reformation in der Stadt Metz, in der Kaufmannsstadt Saint-Nicolas-de-Port im Bistum Toul sowie in Verdun schnell eine beachtliche Zahl an Anhängern gefunden ${ }^{59}$, auch wenn das ländliche Lothringen mit seiner eher ungebildeten und bäuerlich geprägten Bevölkerung insgesamt letztlich ein »terrain peu favorable« (Guy Cabourdin) ${ }^{60}$ für reformatorische Ideen darstellte. Auf Dauer etablieren konnte sich lediglich die protestantische Gemeinde in Metz, deren Anhänger in der Folgezeit vor allem durch ihre Königstreue bedeutsam werden sollten.

\section{Verwaltung und Gerichtsbarkeit vor der französischen Einflußnahme}

Um die von französischer Seite nach 1552 intendierten und durchgeführten Veränderungen im Bereich von Recht und Gerichtsbarkeit bewerten zu können, ist eine Darstellung der Verhältnisse vor Beginn der französischen Einflußnahme unerläßlich. Die von der bisherigen Forschung am besten untersuchten Verhältnisse in Hochstift und Stadt Metz sollen hierbei etwas

${ }^{57}$ CHÂtellier, Lothringen, S. 103; CABOURDIN, Histoire de la Lorraine, Bd. 3,1, S. $28 \mathrm{f}$.

${ }^{58}$ Wobei man sich jedoch keine lückenlose Reihe an "Ersatzbischöfen « vorstellen darf. Zwischen den Jahren 1497 und 1518 sowie 1529 und 1550 entbehrte beispielsweise das Bistum Metz auch eines Suffraganbischofs. Insgesamt bekamen die Gläubigen ihren Oberhirten nur höchst seiten zu Gesicht - selbst bei ihrer Amtseinsetzung ließen sich die Metzer Bischöfe Henri de Lorraine, Jean de Lorraine und Charles de Lorraine-Guise durch Koadjutoren oder Weihbischöfe vertreten. Robert Folz, der die Bischofswahlen im Metz der frühen Neuzeit untersucht hat, schreibt hierzu: "Les bénéfices sont considérés comme de simples machines à donner de l'argent, un moyen de récompense et de dotation; on les marchande, on les échange comme on veut sans se préoccuper des fidèles qui forcément sont abandonnés à eux-mêmes «, FolZ, Concordat, S. 229.

591525 zählte man in der Stadt bereits etwa 500 entschiedene Anhänger der Reformation (bei einer Einwohnerzahl in Stadt und Umland von etwa 30000 ), zu denen sich schon bald einige der einflußreichsten Familien der Stadt gesellen sollten. ZELLER, Réunion, Bd. 1, S. 187f. und TRIBOUT DE MOREMBERT, Diocèse de Metz, S. 108f. Zum Protestantismus in Lothringen allgemein vgl. CABOURDIN, Histoire de la Lorraine, Bd. 3,1, S. 37-46, 105-126, sowie den Sammelband von CHÂTELLIER (Hg.), Les réformes en Lorraine.

${ }^{60}$ CABOURDIN, Histoire de la Lorraine, Bd. 3,1, S. 37. 
ausführlicher behandelt werden, da sie in vielem Rückschlüsse auf die beiden anderen Hochstifte und Städte zulassen.

\subsection{Verwaltung und Gerichtsbarkeit im Hochstift Metz}

Die Gerichtsbarkeit in erster Instanz oblag in Zivil- wie Kriminalsachen den Ortsgerichten auf der Ebene der Kastellaneien ${ }^{61}$. Diese Gerichte waren zustän$\mathrm{dig}$, wenn ausschließlich unfreie Untertanen ${ }^{62}$ beteiligt waren, die zudem im jeweiligen Gerichtsbereich ansässig waren. Theoretisch wurde zwischen hoher, mittlerer und niederer Gerichtsbarkeit unterschieden ${ }^{63}$. Die Richter an den Ortsgerichten waren rechtskundige Laien aus dem jeweiligen Gerichtsbezirk. Die einzelnen Ämter waren die der Schöffen (échevins) und des Bürgermeisters (maire) als Vorsitzenden. Der Kastellan (châtellain) als Amtsträger des Bischofs wohnte den Gerichtstagen ebenfalls bei $^{64}$. Ursprünglich wurden wahrscheinlich sowohl der maire als auch die Schöffen gewählt ${ }^{65}$. Nicht nur die Wahl der Schöffen spricht für eine relative Selbständigkeit dieser Gerichte, sondern auch die schwache Position des Kastellans als Vertreter des Bischofs: Er war zwar anwesend, hatte aber die Entscheidung der anderen zu akzeptie-

${ }^{61}$ Von der Tätigkeit dieser Gerichte und ihrem genauen Aufbau ist denkbar wenig überliefert. Akten dieser Gerichte sucht man vergebens, und ihre Zusammensetzung aus Laienrichtern legt nahe, daß die gesamten Verfahren mündlich abliefen. Diese Vermutung scheint auch das Inventar des bischöflichen Archivs von $1767 \mathrm{zu}$ bestätigen. Dort werden unter der Rubrik justice locale bis 1648 nur 16 Aktenstücke - darunter keine eigentlichen Gerichtsakten - aufgezählt. Vgl. A.D. Moselle, G 37, fol. 208 r.

${ }^{62}$ Denkschrift von 1607, in: HAMMERSTEIN, Der Metzer Bischof, S. 162.

${ }^{63}$ Diese Unterscheidung erlangte aber ausschließlich in den Lehnsherrschaften des Bischofs Bedeutung, denn nur dort konnten die einzelnen Gerichtsbarkeitsrechte bei verschiedenen Herren liegen. Vgl. Coutumes générales de l'évêché de Metz, commentés par M. DLANGE, Enrichis d'une table des matières mise en ordre alphabétique, La Haye 1772, Titre 5, Art. I XX. sowie Commentaire, Art. 5.

${ }^{64}$ So in Baccarat, vgl. Registre et papier terrier portant déclaration particulière et par le menu des tous les droits régaliens et seigneuriaux, cens, rentes,...(etc.) vom 23.01.1605, abgedruckt bei Henri LEPAGE, Le département de la Meurthe, Statistique historique et administrative, 2 Bde., Nancy 1865, hier Bd. 1, S. 72-76 (allerdings gab es hier neben den Schöffen noch Geschworene (jurés)). Schöffen und maire findet man auch in Albestroff, vgl. PROST, Albestroff, S. 9 und 17; und in Vic, vgl. A.D. Moselle, G 37, fol. 208 r.

${ }^{65}$ Im Inventar von 1767 findet sich unter den Aktenstücken der justice locale von Vic ein acte d'élection d'un échevin en la justice locale - die auf eine Wahl der Schöffen - wohl durch die Gerichtsgemeinde - hindeutet, A.D. Moselle, G 37, fol. 208 r. Eine Art Weistum aus der Kastellanei Baccarat von 1605 besagt, daß der maire ursprünglich von den Bewohnern gewählt wurde, nun aber bereits seit längerer Zeit vom Kastellan eingesetzt werde. Die übrigen Beamten der lokalen Justiz, die in Baccarat als zwei Geschworene (jurés) und ein Schöffe (échevin) bezeichnet werden, wurden nach dem Dokument von den Amtsträgern des Vorjahres gewählt. Vgl. LEPAGE, Département de la Meurthe, S. 73f. 
ren $^{66}$. Der Kastellan selbst hatte im 16. Jahrhundert also keine Gerichtsgewalt über die Einwohner seiner Verwaltungseinheit inne, sondern mußte sich sogar mit Klagen gegen diese selbst an die örtlichen Gerichte wenden ${ }^{67}$.

Die relativ starke Stellung der Ortsgerichte war weiterhin in ihren rechtlichen Zuständigkeiten begründet. Sie urteilten in allen Straf- und fast allen Zivilsachen. In Strafsachen war ihre Entscheidung jeder Kontrolle entzogen, denn eine Berufung war nicht vorgesehen ${ }^{68}$. Dem Angeklagten blieb nur noch die Möglichkeit, den Bischof um Gnade zu bitten ${ }^{69}$. Bei Urteilen der lokalen Gerichte in Zivilsachen hingegen war eine Berufung an das ubergeordnete Bailliage-Gericht möglich. Das Bailliage-Gericht war damit die oberste Gerichtsinstanz im Hochstift ${ }^{70}$. Durch seine Zuständigkeit für Berufungen aus dem Hochstift und den abhängigen Lehnsherrschaften hatte das Gericht auch räumlich einen beachtlichen Zuständigkeitsbereich ${ }^{71}$.

Neben der Zuständigkeit als Berufungsgericht war die bailliage in erster Instanz für alle Streitigkeiten zwischen Adligen und Freien, die im Hochstift ansässig waren oder Lehen vom Bischof empfangen hatten, zuständig ${ }^{72}$. Ebenfalls in erster Instanz richtete es bei den sogenannten cas privilégiéz, egal ob

${ }^{66}$ Prost, Albestroff, S. 9.

${ }^{67}$ Ibid. S. 50, Anm. 1 und S. 98.

${ }^{68}$ Coutumes de l'évêché de Metz, Dilange, Commentaire, S. $105 f$.

${ }^{69}$ Nur in seltenen Fällen konnte der Angeklagte in einem Strafverfahren eine Nichtigkeitsklage vor dem Bailliage-Gericht in Vic anstrengen. Denkschrift von 1607, in: HAMMERSTEIN, Der Metzer Bischof, S. 162f.

${ }^{70}$ Vor 1593 war die Zuständigkeit bei Berufungsverfahren offensichtlich noch zwischen dem Bailliage-Gericht in Vic und dem Gericht in Marsal geteilt: Die Berufungen der Kastellaneien Haboudange, Fribourg und La Garde, sowie von den Ortsgerichten in Marsal gingen an das Kastellanei-Gericht in Marsal, die übrigen nach Vic (der Vertrag vom 14.12.1593 bestimmte, daß die Dörfer, die vorher nach Marsal appelliert hatten, nun nach Vic ziehen sollten. Nach Max DU PREL, in: Statistisches Bureau für Elsass-Lothringen (Hg.), Das Reichsland Elsass-Lothringen, Landes- und Ortsbeschreibungen, 3 Bde., Straßburg 1898-1901, hier Bd. 2, S. 632). Ursprünglich amtierte in Marsal wohl auch ein zweiter bailli (dieser Hinweis bei BOUR, Histoire de Metz, S. 84. Wie lange der zweite bailli amtierte, wäre noch einmal genau an den Akten, vor allem den Kapitularien zu überprüfen. Bei den Recherchen zu der vorliegenden Arbeit konnte in den Akten des Hochstifts im 16. Jahrhundert kein Hinweis auf einen zweiten bailli gefunden werden. Von Interesse ist hierbei, daß bis zum Jahre 1548 am Gericht von Marsal in deutscher Sprache verhandelt wurde, während am Gericht in Vic das Französische Amtssprache war. Die Zuständigkeit des Appellationsgerichtes in Marsal deckte sich, abgesehen von der Kastellanei Albestroff, also genau mit den Gebieten des Hochstiftes, die im deutschen Sprachraum lagen. Vgl. Ordonnanz von Jean de Lorraine, 28.2.1548, abgedruckt in WITTE, Deutschtum, S. $299 \mathrm{f}$.

${ }^{71}$ Im Hochstift Metz reichte er im Osten jedoch auch in den Lehnsherrschaften nicht über die Saar hinaus, da die Vasallen von jenseits der Saar das Privileg hatten, daß Berufungen von ihren Ortsgerichten direkt an das Reichskammergericht gingen, ohne die Zwischeninstanz der bailliage. Denkschrift von 1635, A.D. Moselle, G 24 (22), fol. 1v.

${ }^{72}$ Denkschrift von 1607 in: HAMMERSTEIN, Der Metzer Bischof, S. 163. 
zwischen Adligen oder Bürgerlichen ${ }^{73}$. Zu diesen gehörten Streitigkeiten, die die Erhebung von Steuem betrafen ${ }^{74}$, Beleidigungen, Klagen wegen unerlaubter Handlung, Widerstand gegen die Regierungsgewalt und ähnliche Sachverhalte, die man heute als Angelegenheiten von öffentlichem Interesse bezeichnen würde. $\mathrm{Zu}$ beobachten ist hierbei auch, daß sich die bischöflichen cas privilégiéz weitgehend mit den sogenannten cas royaux im Königreich Frankreich deckten, die unter die direkte Zuständigkeit der königlichen Berufungsgerichte fielen ${ }^{75}$. Als Berufungsgericht für die Ortsgerichte sowie die Justiz der Lehnsherren übte das Bailliage-Gericht damit eine wichtige Kontrollfunktion über die niedere Gerichtsbarkeit aus, die noch durch die Möglichkeit von Nichtigkeitsklagen verstärkt wurde. Ausdruck dieser Kontrollfunktion war auch, daß es die Höhe der von den Ortsgerichten verhängten Geldstrafen fest$\operatorname{legte}^{76}$, also selbst regelnd tätig wurde. Auch im Bereich der administrativen Aufgaben, die der bailliage vor allem im Bereich der Wirtschaft und Aufsicht über den Handel zukamen, erließen es Verordnungen ${ }^{77}$.

Das Bailliage-Gericht änderte seine Zusammensetzung in der Frühen Neuzeit mehrfach. In der Mitte des 16. Jahrhunderts, aus der die ersten Akten überliefert sind, stand es unter dem Vorsitz des lieutenant oder des bailli. Die 13 bis 14 Richter wurden als maires und échevins (Schöffen) bezeichnet ${ }^{78}$, was darauf schließen läßt, daß diese vermutlich Laien waren.

Eine weitere Instanz der Gerichtsbarkeit im Hochstift Metz waren die sogenannten assises, die aus dem bailli, sowie aus den Adligen, die Lehen im Hochstift besaßen, zusammengesetzt waren ${ }^{79}$. Dieses Gericht entschied über Lehnssachen und alle Streitigkeiten, die adligen Grundbesitz betrafen und für die das Bailliage-Gericht nicht zuständig war ${ }^{80}$. Dort wurden aber auch, wie in einem Rat, alle Angelegenheiten der Vasallen besprochen. Das Verfahren an diesem Gericht lief ähnlich ab wie bei den Schöffengerichten der Stadt Metz und am herzoglich-lothringischen Assisengericht: Für jeden Fall wurde aus den Reihen der Anwesenden einer ernannt, der der Verhandlung vorstand, und

${ }^{73}$ Ibid.

${ }^{74}$ Im Herzogtum wurden diese Fälle von einem eigenen Gericht entschieden, der chambre des comptes, vgl. DUVERNOY, Alphonse de Rambervillers, S. 285.

${ }^{75} \mathrm{Zu}$ den cas royaux vgl. Guy CABOURDIN, Georges VIARD, Lexique historique de la France d'ancien régime, Paris 1990, S. 51.

${ }^{76}$ Bischöfliche Ordonnanz vom 25.2.1579, A.D. Meurthe-et-Moselle, Série B, Sentences Vic 1579-80, fol. 22v.

${ }^{77}$ So wurde 1566 eine Regelung zur Beschränkung der Weinpreise im Hochstift Metz erlassen. Vgl. DUVERNOY, Alphonse de Rambervillers, S. 285.

${ }_{78}$ A.D. Meurthe-et-Moselle, Série B, Sentences Vic 1535-38, fol. 135 und Sentences Vic 1552-54, fol. 49.

${ }^{79}$ Denkschrift von 1607, in: HAMMERSTEIN, Der Metzer Bischof, S. 163.

${ }^{80}$ Neuregelung der Rechtstage 1564, die auch den vorherigen Zustand referiert: A.D. Moselle, 2F14, fol. 41(bis)r. Das Gericht tagte alle zwei Monate auf Einladung des bailli. 
nachdem er den Rat der anderen Richter angehört hatte, das Urteil verkünde$\mathrm{te}^{81}$. Genau wie in der Stadt wurde, wenn Uneinigkeit unter den Richtern herrschte, ein neuer Gerichtstermin festgeleg ${ }^{82}$. Das Verfahren wurde auch an den französischen Parlamenten gepflegt, wo in der mündlichen Verhandlung ebenfalls immer ein rapporteur bestimmt wurde, der das Verfahren und die Ermittlungen leitete ${ }^{83}$. Von den assises war ebenfalls eine Appellation ans Reichskammergericht möglich ${ }^{84}$.

\subsection{Städtische Verwaltung in Metz}

Die Stadt Metz stand in sehr viel geringerem Maße, als dies in Toul und Verdun der Fall war, in Beziehung zu ihrem Bischof und seinem Territorium. Betrachtet man die städtische Gerichtsbarkeit in Metz, so fällt zunächst ihre Eigentümlichkeit in Organisation wie Begrifflichkeit ins Auge: Die Institutionen der städtischen Gerichtsbarkeit waren alle sehr alt, hatten jedoch ihre Besetzung und ihre Zuständigkeiten im Laufe der Jahrhunderte mehrfach verändert ${ }^{85}$. Aufgrund ihres unterschiedlichen Alters und Ursprungs (Institutionen der älteren Stadtgemeinde bzw. Institutionen, die durch die Paraigenregierung geschaffen wurden) überschnitten sich teilweise die Zuständigkeiten der einzelnen Gerichtsbarkeiten. Fast alle Institutionen der Gerichtsbarkeit hatten darüber hinaus auch politische Aufgaben.

Wichtigste Institution der Gerichtsbarkeit war der Rat der Dreizehn (Treize). Obwohl er im Gegensatz zu den übrigen Institutionen noch relativ jung war ${ }^{86}$, hatte er nach und nach so viele gerichtliche Kompetenzen angesammelt, da $B$ er für die Metzer Bürger schlechthin La justice verkörperte und auch so bezeichnet wurde ${ }^{87}$. Der Rat der Dreizehn wurde aus und von den Mitgliedern der patrizischen Oberschicht jährlich gewählt. Diese Institution, die auch in der gesamten Verwaltung der Stadt eine führende Rolle spielte, war zunächst vor allem für die Wahrung des innerstädtischen Friedens zuständig. Entsprechend lag bei den Dreizehn die Gerichtsbarkeit in sämtlichen Polizei- und Strafsachen sowie bei Angelegenheiten öffentlichen Interesses ${ }^{88}$. Darüber hinaus be-

${ }^{81}$ François de VAN DER STRATEN-PONTHOZ, Un procès au quinzième siècle devant la cour de Vy, Jean de Toullon, in: Mémoires de la société d'archéologie et d'histoire de la Moselle 5 (1863) S. 79-102, hier S. 86f.

${ }^{82}$ VAN DER STRATEN-PONTHOZ, Un procès, $S$. 86f.

${ }^{83}$ Vgl. Kapitel II.4.

${ }^{84}$ Denkschrift von 1607, in: HAMMERSTEIN, Der Metzer Bischof, S. 163.

${ }^{85}$ Hier soll nur auf den status quo im 16 . Jahrhundert eingegangen werden.

${ }^{86}$ Der Rat war im 13. Jahrhundert zunächst als bischöfliche Institution entstanden, vgl. dazu Prost, Institutions judiciaires, S. $71 \mathrm{f}$.

${ }^{87}$ Ibid. S. 9.

${ }^{88}$ Ibid. S. 77-86. 
saßen sie auch richterliche Kompetenzen im zivilrechtlichen Bereich. Hier konkurrierten sie mit den Schöffengerichten unter der Leitung des Schöffenmeisters (maître-échevin). Die Kläger konnten wählen, wo sie ihre Klage vorbringen wollten.

Die Strafgerichtsbarkeit konnten die Dreizehn jedoch nicht alleine ausüben, sondern sie wurden hierbei von den comtes jurés unterstützt. Die 25 comtes waren die einzigen Mitglieder der Stadtverwaltung, die nicht aus dem Patriziat stammten. Im 16. Jahrhundert war ihre Rolle im Strafprozeß jedoch nur noch gering: Zum einen wurden die Kandidaten zwar vom Volk der einzelnen Pfarreien gewählt, wer von diesen Kandidaten jedoch dann zum comte ernannt wurde, bestimmten allein die Mitglieder der patrizischen Oberschicht ${ }^{89}$. Vor allem aber mußten die comtes in ihren Entscheidungen stets den Dreizehn folgen $^{90}$. Auch in den Angelegenheiten von öffentlichem Interesse sowie bei sonstigen Gerichtsverfahren von großer Wichtigkeit urteilten die Dreizehn nicht allein. Hierbei wurden sie vom großen Rat der Stadt, dem conseil, später auch conseil des Treize genannt, unterstützt ${ }^{91}$. Gegen die Urteile der Dreizehn konnte Berufung beim Gericht des Schöffenmeisters eingelegt werden ${ }^{92}$.

Dieser nahm die ehrwürdigste Position innerhalb der städtischen Verwaltung ein. Der maître-échevin war der oberste Richter und das Oberhaupt der Stadt $^{93}$. Sein Amt ist aus der Institution der Schöffen hervorgegangen ${ }^{94}$. Er wurde im 16. Jahrhundert immer abwechselnd von einer der sechs Patrizierfamilien gestellt ${ }^{95}$. Prinzipiell erstreckte sich die im Gegensatz zu den anderen Ämtern nirgends ausdrücklich umschriebene Gerichtsgewalt des Schöffenmeisters wohl über alle Polizei-, Straf-, und Zivilsachen, die vor ihn gebracht wurden $^{96}$. Tatsächlich war sein Gericht in erster Linie Berufungsinstanz für die Gerichtsbarkeit der Dreizehn. In erster Instanz konnte er in zivilrechtlichen Angelegenheiten, vor allem in Vormundschaftssachen, Recht sprechen. Seine Urteile, die dits pour droit, bildeten zudem als Sammlung von Präzedenzfällen das Gewohnheitsrecht der Stadt ${ }^{97}$.

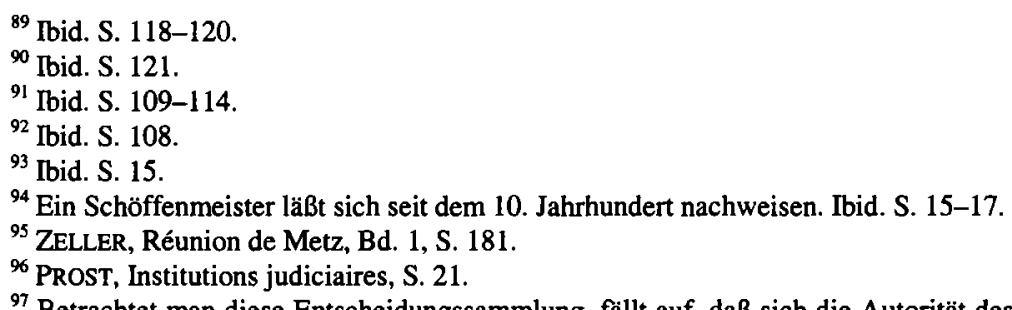

${ }^{97}$ Betrachtet man diese Entscheidungssammlung, fältt auf, daß sich die Autorität des Schöffenmeisters über das eigentliche Einflußgebiet der Stadt hinaus auf das bischöfliche Territorium ausdehnte. In den überlieferten Entscheidungen der Jahre 1500-1523 häufen sich die Berufungen von Gerichten aus dem bischöflichen Gebiet. Es finden sich Appellationen von Ortsgerichten, von Gerichten aus Lehnsgebieten des Bischofs von Metz, für die normalerweise die bailliage in Vic zuständig war, aber auch Berufungen von der bailliage in Vic 
Wenn der Schöffenmeister Gericht hielt, wurde er von mindestens sechs Mitgliedern seines Rates unterstützt. Dieser setzte sich aus den 21 Schöffen $^{98}$ der Stadt sowie aus einzelnen Männern seines Vertrauens zusammen, die jedoch auch aus den paraiges stammen mußten. In kleineren zivilrechtlichen Angelegenheiten urteilten einzelne Gerichte, die sich aus einigen der oben genannten 21 Schöffen zusammensetzten, ohne den Schöffenmeister. Genau wie die Urteile des Gerichts des Schöffenmeisters selbst ergingen auch diese Urteile in letzter Instanz. Eine Berufung gab es lediglich in einigen Fällen an das Reichskammergericht ${ }^{99}$. Trotz ihres Ansehens war die Gerichtsbarkeit des maittre-échevin sowie der Schöffengerichte durch zwei Tatsachen beschränkt: Zum einen lag die Exekutionsgewalt der Urteile allein beim Rat der Drei$z_{\text {ehn }}{ }^{100}$, zum anderen konnte vor diesen Gerichten nur eine Klage erhoben werden, die durch den plaid banni, das heißt unter der Banngewalt von einem der drei Bürgermeister der Stadt, erhoben wurde ${ }^{101}$. Der Ablauf eines solchen Verfahrens war aufwendig und angefüllt mit überalterten Formalitäten ${ }^{102}$. Das Verfahren war ähnlich dem, das vor den bischöflichen wie auch den herzoglich-lothringischen Adelsgerichten (assises) angewendet wurde ${ }^{103}$.

\subsection{Verwaltung und Gerichtsbarkeit in Stadt und Hochstift Toul}

Grundsätzlich unterscheiden sich die Institutionen in Toul und Verdun von denen in Metz eher durch die Terminologie als durch ihre Funktionen. So

selbst, für die normalerweise das Reichskammergericht zuständig gewesen wäre. Vgl. hierzu Jean-Jacques SALVERDA DE GRAVE, Eduard Mauritz MEIJERS, Jean SCHNEIDER ( $\mathrm{Hg}$.), Le droit coutumier de la ville de Metz au Moyen Age, Bd. 3: Jugements du Maître-Échevin du $X^{e}$ et XVI siècle, Haarlem 1951, hier S. VII, sowie die Entscheidungen der entsprechenden Jahrgänge.

${ }^{98}$ Diese Zahl bei BouR, Histoire de Metz, S. 78.

${ }^{99}$ PrOST, Institutions judiciaires, S. 48-51.

${ }^{100}$ Ibid. S. 19.

${ }^{101}$ Die genaue Schilderung eines solchen, schon im 16. Jahrhundert archaisch wirkenden plaid banni und seiner vorgeschriebenen Formeln findet man bei PROST, Institutions judiciaires, S. 23.

${ }^{102}$ Wie einer genau vorgeschriebenen Rede und Gegenrede zwischen maire und Schöffenmeister bzw. dem Vorsitzenden des einfachen Schöffengerichts (dem maître des échevins). Diese enthielt auch noch Überreste einer ursprünglich bei den maires liegenden Gerichtsgewalt: So wiederholte der maire mehrfach die Formel je le mets en votre jugement vgl. ibid. S. 57-59.

${ }^{103} \mathrm{Vgl}$. oben, Kapitel II.3.1. Der maire bestimmte einen der anwesenden Schöffen zum Vorsitzenden der Verhandlung, der auch das Urteil verkündete. Vorraussetzung für die Gültigkeit des Urteils war die Einstimmigkeit aller Schöffen. War diese nicht gegeben, wurde vom maître-échevin ein neuer Verhandlungstermin mit anderen Richtern angesetzt. PROST, Institutions judiciaires, S. 55, 61 zum Verfahren der herzoglichen Assisen. Zu den bischöflichen Assisen allgemein vgl. VAN DER STRATEN-PONTHOZ, Un procès, S. 79-102. 
agierten auch in den einzelnen Verwaltungseinheiten des bischöflichen Territoriums von Toul lokale Gerichte unter der Aufsicht des Kastellans oder prévôt, die in erster Instanz mit allen Verfahren unter Nicht-Adligen befaßt waren. Ebenso wie im Hochstift Metz weiß man jedoch nur wenig über die Arbeit dieser Gerichte. Die Berufungen gegen Urteile der lokalen Gerichte gingen vor das Bailliage-Gericht des Hochstifts Toul. Dieses war offenbar ähnlich organisiert wie das entsprechende Gericht im Hochstift Metz ${ }^{104}$.

Besser unterrichtet ist man über die Organisation der städtischen Gerichtsbarkeit in Toul ${ }^{105}$. Wie bereits erwähnt, wurde der Magistrat vom Bischof aufgrund von Vorschlagslisten ernannt. Er setzte sich zusammen aus dem Rat, dem Schöffenmeister, den dix justiciers, dem procureur général und einem receveur (der für den gesamten städtischen Haushalt verantwortlich war) ${ }^{106}$. Die Gerichtsbarkeit lag hauptsächlich bei den dix justiciers, die als erste Instanz in Zivilsachen urteilten ${ }^{107}$. In Strafsachen hingegen wurden kleinere Vergehen von einem weiteren Gremium, den cinq enquéreurs, verfolgt, die Polizeiaufgaben wahrnahmen und hierbei auch die Gerichtsbarkeit über alle Delikte hatten, die nicht mit Körperstrafen oder Verbannung geahndet wur$\operatorname{den}^{108}$. Bei schweren Delikten wurde der Fall vor den Rat, den Schöffenmeister und die Schöffen (oder élus) der Stadt gebracht ${ }^{109}$. In allen Verfahren hatte der procureur der Stadt (auch Syndicus, syndic genannt), der vor allem die Aufgabe hatte, über die städtischen Privilegien zu wachen, eine beratende Stimme ${ }^{110}$.

In Strafsachen urteilten die städtischen wie die ländlichen Lokalgerichte ohne Berufungsmöglichkeit, während bei Zivilprozessen eine Berufung gegen die Urteile der städtischen Gerichte und der bischöflichen bailliage vor dem sogenannten conseil épiscopal oder chambre épiscopale möglich war. $\mathrm{Zu}-$ sammengesetzt war dieses Gericht offensichtlich je zur Hälfte aus Laien und

${ }^{104}$ Eine Denkschrift aus dem Jahr 1631/1632 berichtet von der Berufungsmöglichkeit vor diesem Gericht und davon, daß der Bischof über einen bailli, einen lieutenant und einen procureur verfüge. Vgl. AMAE, CP Lorr. 10, fol. 178-179.

${ }^{105}$ Hierüber unterrichten uns die Memoiren des Jean du Pasquier, vgl. PASQUIER, Mémoires, hg. v. DaULNoY, PILLEMENT, v.a. S. 8-11. Die Situation in Toul, vor allem das Verhältnis von Domkapitel und Stadtgemeinde, im 14. und 15. Jahrhundert wurde kürzlich von Damien VAISSE, La communauté urbaine de la cité de Toul du milieu du $\mathrm{XIV}^{\mathfrak{e}}$ à la fin du $\mathrm{XV}^{\mathfrak{e}}$ siècle, thèse, écoles des Chartes, Paris [masch.] 1999, aufgearbeitet.

${ }^{106}$ Zum receveur, dessen Amt nicht besonders beliebt war, vgl. KuNÉGEL, Toul, S. 307-326.

${ }^{107}$ PIMODAN, Réunion, S. XXVI.

${ }^{108}$ BIESEL, Hexenjustiz, S. 105.

${ }^{109}$ Auch hier ist, ähnlich wie in Metz, die Überlappung von älteren und neueren Institutionen gut sichtbar, denn vollstreckt wurden die Urteile wiederum vom maire, einem alten bischöflichen Beamten. Vgl. BIESEL, Hexenjustiz, S. 104f.; PIMODAN, S. XXVIf.

${ }^{110}$ Ibid. S. $107 f$. 
Klerikern ${ }^{111}$. Gegen Urteile dieses Gerichts war wiederum eine Berufung vor das Reichskammergericht möglich.

Die Besitzungen des Domkapitels wurden von einer vollkommen eigenständigen Gerichtsbarkeit kontrolliert. Auch sie verfügten über lokale Gerichte, geleitet von den maires und unter Kontrolle der Vögte oder Kastellane. Die Berufungen dieser Gerichte in Zivilsachen gingen vor das Gericht des siège des appeaux, das aus sechs oder sieben vom Kapitel gewählten Kanonikern bestand $^{112}$. Auch hier war eine Berufung an das Reichskammergericht möglich.

\subsection{Verwaltung und Gerichtsbarkeit in Stadt und Hochstift Verdun}

Eine ähnliche Dreiteilung in bischöfliche, städtische und kapitulare Institutionen wie in Toul findet sich auch in Verdun. Jedoch ist über die einzelnen Institutionen nur wenig bekannt, da sich die entsprechende Forschung entweder auf das hohe Mittelalter oder auf die Zeit nach der umfassenden Verfassungsänderung durch Bischof Psaume nach 1552 konzentriert. Lediglich die Organisation der städtischen Gerichtsbarkeit ist leidlich bekannt: Die wichtigste Zivilgerichtsbarkeit lag in den Händen des doyen der Stadt und seiner Schöffen, sie wurden échevinages du palais genannt und traten in Sainte-Croix zusammen, woher auch der Name des dort geltenden Gewohnheitsrechtes (coutume) rührt. Das Gericht von Sainte-Croix fungierte auch als eine Art Oberhof für die ländlichen Gemeinden des Umlandes, in denen die coutume von Sainte-Croix befolgt wurde ${ }^{113}$. Teile der Zivilgerichtsbarkeit sowie die Kriminalgerichtsbarkeit lagen beim Gericht der jurés du nombre ${ }^{114}$. In Zuständigkeiten und auch in der Terminologie sind hier Parallelen zu den Schöffengerichten und den nach ihrer Zahl benannten Gerichten der dix justiciers bzw. Treize jurés in Toul und Metz deutlich. Alle Amtsträger in Verdun wurden vom Bischof ernannt.

Die bischöflichen Institutionen scheinen ebenfalls denen im Hochstift Toul und Metz geähnelt zu haben: Über der Ebene der lokalen Gerichte agierte das Bailliage-Gericht, und diesem wiederum übergeordnet ein Gericht, das als conseil épiscopal bezeichnet wurde ${ }^{115}$, und neben den Berufungen des Bailliage-Gerichts auch für die Berufungen der städtischen Gerichte (Sainte-Croix

\footnotetext{
111 PIMOdAN, Réunion, S. XXIV.

112 Ibid.

${ }^{113}$ EMMERY, Recueil, Bd. 1, S. 8 (Anm. 1).

${ }^{114}$ Dieses hatte das mittelalterliche Strafgericht der vicomté abgelöst und wurde, vor allem in späteren Quellen, justice ordinaire genannt. Vgl. SCHNEIDER, Cité de Verdun, S. 332f., AIMOND, Rélations, S. 24f.

${ }^{115}$ Auch salle épiscopale oder chambre épiscopale.
} 
und jurés du nombre) zuständig war ${ }^{116}$. Weiterhin agierte eine Art Lehensgericht, vergleichbar mit den Assisen des Hochstifts Metz, die sogenannten hauts-jours oder grands-jours ${ }^{117}$.

Über die Gerichtsbarkeit in den Herrschaftsgebieten des Domkapitels von Verdun ist kaum etwas bekannt, jedoch ist auch hier von lokalen Gerichten auf der Ebene der prévôtés auszugehen. Die Berufungen gegen zivilrechtliche Urteile dieser prévôtés wurden von eigens dazu abgestellten juges commis par le chapitre entschieden. Da all diese Personen Geistliche waren, wurde die Kriminalgerichtsbarkeit in den Gebieten des Domkapitels von einem dazu ernannten Laien, dem écuyer ausgeübt. Gegen seine Urteile war, wie immer in den Trois-Évêchés, keine Berufung möglich ${ }^{118}$. Für ständige Konflikte sollten nach 1552 vor allem die Gerichtskompetenzen des Kapitels im Bezirk des sogenannten cloitre innerhalb der Stadt sorgen, die vom Magistrat immer wieder bestritten wurden ${ }^{119}$. Eine Berufung von den kapitularen Gerichten vor dem bischöflichen Gerichtshof war nicht möglich, jedoch konnte, genau wie bei den bischöflichen Gerichten, in Zivilsachen vor dem Reichskammergericht Berufung eingelegt werden ${ }^{120}$.

\subsection{Coutume und Reichsrecht}

In ganz Lothringen war, wie überall in Nordfrankreich, die Grundlage aller Rechtsprechung ein lang geübtes Gewohnheitsrecht, die coutume. Jeder Ort hatte wseine « coutume, die vor allem das Zivil- und Prozeßrecht regelte und mündlich überliefert wurde. Die Mündlichkeit und die starken regionalen Unterschiede machten die Rechtsprechung nach diesem Gewohnheitsrecht außerordentlich schwierig $^{121}$. Im Gebiet der Trois-Évêchés wurde es erst nach 1552,

${ }^{116}$ BnF, Cinq-Cents Colbert 440, fol. 253f.; A.D. Mos. B 10954 und 11082; AIMOND, Rélations, S. 19-22 ; A.D. Meuse 11 F 14, S. 151 .

${ }_{117}$ AIMOND, Rélations, S. 20; BnF, Cinq-Cents Colbert 440, fol. 253f. A.D. Moselle, B 10855; A.D. Meuse 11 F 14, S. $151 f$.

${ }_{118} \mathrm{Vgl}$. die Ausführungen von EMMERY, Recueil, Bd. 1, S. 182 (Anmerkungen).

119 Petitot-Bellavène, Deux siècles, S. $147 \mathrm{f}$.

${ }^{120}$ AlMOND, Rélations, S. 21.

${ }^{121}$ Meist versuchte jede Partei nachzuweisen, daß die Gewohnheit für eine Entscheidung zu ihren Gunsten spreche. In solch strittigen Fällen kam es dann zu einer sogenannten enquête par turbes, das heißt, ein oder mehrere Abgesandte des Gerichtes gingen in den betreffenden Ort und legten dort mindestens zwei Gruppen von zehn sapientes - den turbes - die strittige Rechtsfrage vor. Vgl. dazu: Leo RICHARD, Coutumes, usages locaux und modernes Recht in Lothringen, in: Jahrbuch der Gesellschaft für lothringische Geschichte und Altertumskunde 21 (1909) S. 164-229, hier S. 166. Zwei Reichskammergerichtsprozesse aus den TroisÉvêchés weisen in ihren Akten die Ergebnisse einer solchen Befragung auf. A.D. Moselle, B 10886 und 10887 sowie B 10938. 
also schon unter einem gewissen französischen Einfluß aufgezeichnet ${ }^{122}: \mathrm{Zu}$ erst im Hochstift Metz 1601, allerdings dort noch eher auf herzoglich-lothringische denn auf königliche Initiative, dann in der Stadt Metz 1618, während für die coutume von Verdun ein erstes gedrucktes Exemplar aus dem Jahr 1653 gefunden werden konnte ${ }^{123}$ und die Aufzeichnung in Toul erst 1747 erfolgte ${ }^{124}$.

Trotz des Begriffs coutume, der ausdrücklich das alte Herkommen der Rechtsvorschriften unterstreichen sollte, wurden diese Bestimmungen anläßlich ihrer Niederschrift überarbeitet und vereinheitlicht. Deshalb ist kaum noch feststellbar, wie die Bestimmungen des Gewohnheitsrechts in den untersuchten Gebieten vor dieser schriftlichen Fixierung aussahen ${ }^{125}$. Lediglich für Toul läßt es sich in Teilen erschließen, weil hier, anders als in Verdun und Metz in weiten Teilen ein vulgarisiertes römisches Recht angewendet wurde ${ }^{126}$. Gemeinsam ist allen Gewohnheitsrechten, daß sie fast ausschließlich das Zivilrecht einer Regelung unterzogen. Auch darin wird die Verbindung zum französischen Rechtsraum deutlich.

Die Rechtszersplitterung im lothringischen Raum war entsprechend der territorialen Situation sehr ausgeprägt. Noch zur Zeit der Aufzeichnungen im 17. Jahrhundert unterschied sich das Gewohnheitsrecht der Stadt Metz in ganz zentralen Punkten von dem des Hochstiftes Metz. In dieser coutume de l'évêché de Metz, deren Niederschrift zu einer Vereinheitlichung der Rechtsverhältnisse im Territorium beitragen sollte, gab es wiederum eine Sonderregelung für die Gebiete in den Vogesen mit einem ganz anderen Erb- und ehelichen Güterrecht ${ }^{127}$. Die coutumes et droits de Sainte-Croix, die in Verdun befolgt wurden, waren wiederum ein eigenständiges Recht, das ebenfalls vor

122 In Frankreich wurde 1454 beschlossen, die coutumes in einer amtlichen Sammlung schriftlich festzulegen und damit auch zumindest regional zu vereinheitlichen (Ordonnanz von Montils-les-Tours). Diese Kodifikation erfolgte mit einiger Verzögerung je nach Region im Laufe des 15. und 16. Jahrhunderts. Vgl. François-Xavier EMMANUELLI, État et pouvoirs dans la France des XVI'-XVIIr siècles. La métamorphose inachevée, Paris 1992, S. 128.

${ }^{123} \mathrm{Vgl}$. Albert RONSIN, Répertoire bibliographique des livres imprimés en France au XVII ${ }^{\mathrm{c}}$ siècle, Bd. 10: Lorraine - Trois-Évêchés, Baden-Baden 1984 (Bibliotheca Bibliographica Aureliana, 98), S. 41. Das älteste coutume-Exemplar der Bibliothèque nationale de France datiert noch später, auf das Jahr 1678.

${ }^{124}$ Cabourdin, Histoire de la Lorraine, Bd. 3,1, S. $162 f$.

${ }^{125}$ Für das Hochstift Metz existierte eine solche Bestandsaufnahme, die als Vorarbeit zur Redaktion der coutume entstanden war. Das Manuskript, das leider im Krieg zerstört wurde, läßt sich noch im alten Katalog der Stadtbibliothek Metz nachweisen (alte Sign. Ms. 27).

${ }^{126}$ CABOURDIN, Histoire de la Lorraine, Bd. 3,1, S. 163. Vgl. dazu auch Gaston MARCHAL, Droit coutumier de la vilie de Toul. Législation civile et criminelle, organisation judiciaire et procédure, Nancy 1902.

${ }^{127}$ Coutumes générales de l'évêché de Metz, Anhang: Aucuns articles tenus, gardez \& observez ou Coutumes municipales en la Ville \& Chastellenie de Remberviller, Baccarat \& Moyen, Art.I-XXII. 
allem im Bereich des Erbrechts besondere Regelungen beinhaltete ${ }^{128}$. Weiterhin war der Geltungsbereich der Rechte nicht unbedingt deckungsgleich mit dem Territorium. So galt in den Dörfern des Hochstifts Verdun teilweise die coutume des herzoglichen Saint-Mihiel oder die von Clermont, von Luxembourg, das Gewohnheitsrecht des Vermandois oder die charte de Behmont aus dem Jahr 1320. Andererseits wiederum wurde die coutume von Sainte-Croix auch außerhalb des bischöflichen Gebietes angewendet ${ }^{129}$.

Die Stadt Metz besaß neben dem Gewohnheitsrecht der coutume schon relativ früh ein schriftlich fixiertes Spruchrecht, die Entscheidungen des Schöffenmeisters. Diese sogenannten dits-pour-droit ${ }^{130}$ bildeten eine umfangreiche Sammlung von Einzelfallentscheidungen im Zivilrecht, die, vielleicht vergleichbar mit dem angelsächsischen civil law, als Präzedenzfälle für zukünftige Richter dienten ${ }^{131}$. Hierbei handelte es sich jedoch nicht um eine offizielle Sammlung, sondern um private Aufzeichnungen, die innerhalb der Patrizierfamilien von den Vätern an die Söhne weitergegeben wurden ${ }^{132}$. Das Strafrecht sowie die innere Organisation der Stadt wurden durch die sogenannten atours geregelt, Verordnungen, die ebenfalls vom Schöffenmeister zusammen mit den anderen städtischen Amtsträgern beschlossen wurden ${ }^{133}$. Auch die Stadt Verdun besaß mit dem livre des droits eine ähnliche Sammlung von Urteilen und Rechtsgewohnheiten, die wohl im 15. Jahrhundert schriftlich gefaßt wurde, aber weit in das Mittelalter hineinreicht ${ }^{134}$.

Neben diesen Rechtsaufzeichnungen und Gewohnheiten hatte nicht nur in Toul das römische Recht seinen Siegeszug angetreten, vermittelt vor allem durch die geistlichen Gerichte ${ }^{135}$. Dieses Recht ist, genau wie die mündlich tradierten coutumes und die Entscheidungen etwa des Schöffenmeisters von Metz, vor allem im Bereich des Zivilrechts angewendet worden. Die praktische Bedeutung des römischen Rechts ist schwer zu beurteilen und müßte an-

${ }^{128}$ Gemeint ist der im Umland erlaubte, in der Stadt verbotene retrait lignager. Vgl. GIRARDET, in: DERS. (Hg.), Histoire de Verdun, S. 102.

${ }^{129} \mathrm{Vgl}$. die Aufstellung der verschiedenen coutumes und Geltungsbereiche in der Schrift des Dupont de Roucemont, A.D. Meuse, 11 F 15, 16.

$130 \mathrm{Vgl}$. BOUR, Histoire de Metz, S. 78.

${ }^{131}$ Die Entscheidungen des Metzer maître-échevin vom 14. bis 16. Jahrhunderts sind ediert: SALVERDA DE GRAVE, MEIJERS, SCHNEIDER, Droit coutumier, Bd. 1 und 3.

${ }^{132}$ Ibid. Bd. 3, S. I-III.

${ }^{133}$ Aloys RUPPEL, Metz, in: DERS. (Hg.), Lothringen und seine Hauptstadt. Eine Sammlung orientierender Aufsätze, Metz 1913, S. 316-342, hier S. 329.

${ }^{134}$ Dieses Werk ist ediert von Jean-Jacques SALVERDA DE GRAVE, Eduard Mauritz MEIERS, Le Livre des droits de Verdun, Haarlem 1940. Vgl. zu dem Manuskript die dortige Einleitung.

135 Zur Bedeutung des römischen Rechts in Frankreich: EMMANUELLI, Etat et pouvoirs, S. 129. 
hand der entsprechenden Gerichtsakten überprift werden ${ }^{136}$. Sicher ist jedoch, $\mathrm{da} B$ die Offiziale, weltlichen Richter oder Notare, die Recht studiert hatten, in ihrem Studium nur mit kanonischem bzw. römischem Recht vertraut gemacht worden waren, denn die coutumes waren im 16. Jahrhundert kein Gegenstand rechtswissenschaftlicher Betrachtungen oder Lehrveranstaltungen ${ }^{137}$. Es ist anzunehmen, daß Amtsträger mit einem solchen Ausbildungshintergrund schwierige Rechtsfragen dann auch nach dem ihnen geläufigeren römischen Recht entschieden.

Die Trois-Évêchés waren Teil des Reiches, zumindest nominell galten hier auch alle kaiserlichen Erlasse. Bis 1532 bezogen sich diese meist auf das Staatsrecht des Reiches und konnten somit in der täglichen Gerichtspraxis vernachlässigt werden, doch 1532 wurde mit der Carolina das erste Reichsgesetzbuch in Kraft gesetzt, das nun auch in der Gerichtspraxis große Bedeutung erlangen konnte ${ }^{138}$. Theoretisch mußte nun auch im Gebiet der Hochstifte und in den Lehnsherrschaften der Bischöfe nach der Carolina Recht gesprochen werden, zumal es ja kein einheitliches oder gar schriftlich fixiertes Strafrecht gab. Hierfür gibt es jedoch keine Hinweise. Lediglich eine Denkschrift von 1635 zum Hochstift Metz erwähnt vage, daß die Gerichte in Strafsachen selon les formes prescriptes dans l'Empire en la confection des proces criminelz vorgingen ${ }^{139}$. Ob die Carolina jedoch im Hochstift oder in der Stadt Metz tatsächlich praktische Bedeutung erlangt hat, ist schon aus sprachlichen Gründen fraglich. So ist festzustellen, daß es in der Literatur keine Hinweise auf eine Geltung der Carolina in den Trois-Évêchés gibt. Auch bei einer Recherche in den Bibliotheken der Region konnte kein einziges Exemplar dieses Gesetzbuches gefunden werden ${ }^{140}$. Das gleiche läßt sich für 23 Metzer Bibliotheken des 17. Jahrhunderts sagen, deren Inventare Henri Tribout de Morembert ausge-

${ }^{136}$ Die Literatur hat sich bisher noch nicht mit dieser Frage befaßt. In den ältesten Akten der bailliage Vic, die allerdings im Rahmen dieser Arbeit nur sehr flüchtig durchgesehen wurden, sind die gesetzlichen Grundlagen für die Entscheidung nicht ausdrücklich angegeben. Sie müßten also durch eine genaue Einzelanalyse der Urteile im Vergleich mit den jeweiligen Bestimmungen aus coutume und römischem Recht erschlossen werden.

${ }_{137}$ EMMANUELLI, État et pouvoirs, S. 129.

${ }^{138}$ Auf dem Reichstag in Regensburg, auf dem die Carolina endgültig verabschiedet wurde, waren sowohl Vertreter des Bischofs als auch der Stadt anwesend. Über ihre Reaktion auf dieses Gesetzeswerk ist jedoch nichts bekannt. ZELLER, Réunion, Bd. 1, S. 227.

${ }^{139}$ A.D. Moselle, G 24 (22), fol. 1v.

${ }^{140}$ Der Ausstellungskatalog von Philippe Hoch (Hg.), Trésors des bibliothèques de Lorraine, Paris 1998, listet die reichen juristischen Bestände vor allem der Klosterbibliotheken auf, verzeichnet jedoch kein Exemplar der Carolina. Selbst die Vorkriegskataloge der Stadtbibliothek Metz, die über eine sehr reiche Sammlung von Gesetzen und juristischen Schriften aus der ehemaligen Bibliothek der Anwaltskammer verfügt, weisen keinen Text der Carolina, geschweige denn eine Übersetzung auf. Aus Zeitgründen nicht eingesehen werden konnte die Bücherliste der Universität Pont-à-Mousson, A.D. Meurthe-Mos. 4 F 36, 11. Herrn Hoch, Bibliothekar in Metz, danke ich für Hinweise. 
wertet hat. Obwohl er in den Inventaren - die meist den Besitz von juristisch gebildeten Amtsträgern, Mitgliedern der städtischen Führungsschicht oder Klerikern aufführten - zahlreiche juristische Schriften und Ausgaben der coutumes sowie sogar die Akten des Regensburger Reichstages fand, nennt er kein Exemplar der Carolina ${ }^{141}$.

\subsection{Die juristische Ausbildung}

Eine eigene Universität zur Ausbildung von kirchlichen und weltlichen Würdenträgern besaßen die lothringischen Territorien bis zur Gründung einer Universität in Pont-à-Mousson nicht. Jedoch gibt es bereits gegen Ende des 15. Jahrhunderts Hinweise auf einen Rechtsunterricht, der in Vic-sur-Seille angeboten wurde ${ }^{142}$. Die Amtsträger hatten so ganz unterschiedliche Werdegänge hinter sich. Längst nicht alle Amtsträger und nicht einmal alle Richter an den Bailliage-Gerichten hatten Recht studiert ${ }^{143}$. In einem geistlichen Territorium nicht weiter verwunderlich ist die hohe Zahl an Geistlichen, die Ämter in der weltlichen Verwaltung innehatten ${ }^{144}$. Wo die Würdenträger, die studiert hatten, ihre Ausbildungszeit verbracht haben, ist nur sehr schwer herauszufinden. Die Gunst der Studenten teilte sich offensichtlich zwischen den zwei groBen Nachbarn, dem Königreich Frankreich und dem Reich. Am beliebtesten waren die Universitäten von Paris, Köln und Basel ${ }^{145}$. Im rein französischsprachigen Verdun hingegen schien es Studenten noch deutlicher nach Frankreich zu ziehen: Für das Jahr 1579 ist belegt, daß Magistrat und Domkapitel Stipendien zum Studium in Paris und Orléans vergaben ${ }^{146}$.

Seit 1572 verfügte die Region mit der Universität Pont-à-Mousson auch über eine eigene Hochschule, die gemeinsam vom lothringischen Herzog und

\footnotetext{
${ }^{141}$ Henri TRIBOUT DE MOREMBERT, Bibliothèques messines du XVII ${ }^{e}$ siècle, in: Annales de l'est 23 (1971) S. 219-229.

${ }^{142}$ Dieser soll der von dem berühmten Rechtsgelehrten Claude Chansonnette aus Metz erteilt worden sein. Vgl. Adalbert HorawITZ, Briefe des Claudius Canticula und [des] Ulrich Zasius von 1521-1533, Wien 1879, S. 6, 8 .

${ }^{143}$ DuVERnOY, Alphonse de Rambervillers, S. 294.

${ }^{144}$ So waren unter den conseillers des Bailliage-Gerichts in Vic-sur-Seille unter anderem zwei Priester aus der Stadt Vic, der Dekan der Stiftskirche und ein Richter des Offizialgerichtes tätig. Vgl. DUVERNOY, Alphonse de Rambervillers, S. 282f.

${ }^{145}$ Siehe dazu Michel PARISSE, Formation intellectuelle et universitaire en Lorraine avant la fondation de l'université de Pont-à-Mousson, in: L'université de Pont-à-Mousson et les problèmes de son temps, Nancy 1974, S. 17-44, hier S. 28 -30.

${ }^{146}$ A.C. Verdun BB 1 (1579).
} 
dem Kardinal Charles de Lorraine gegründet worden war. Seit 1582 konnte hier neben Theologie auch Recht studiert werden. Damit war den lothringischen Justizeliten eine Ausbildung vor Ort möglich geworden ${ }^{147}$.

\section{Resümee}

Der Blick auf die Situation in den Trois-Évêchés vor den Ereignissen 1552 macht deutlich, daß die drei Reichsterritorien und Städte durch ihre innere Organisation und ihre soziale und wirtschaftliche Verfassung eher instabil waren. Diese Instabilität hatte vor allem zwei Gründe: Zum einen machte der große Einfluß des lothringischen Herzogshauses auf die Bistimer und damit auch die Hochstifte eine eigene Politik der Bischöfe praktisch unmöglich. Zum anderen trug er durch die zahlreichen Verlehnungen von Gebieten und Rechten an den Herzog zur ohnehin problematischen wirtschaftlichen Situation in den Territorien bei. Die Städte hingegen waren regelrecht erstarrt in ihrer mittelalterlichen Verfassung, was zusammen mit dem Machtverfall der aussterbenden Patrizierschicht für innere Spannungen sorgte. Daneben schien die allgemeine Erstarrung auch das Wirtschaftsleben geprägt zu haben, das vor allem in Toul und Verdun noch immer nicht auf die Verlagerung der Handelsströme und Märkte reagiert hatte.

Auch Recht und Gerichtsbarkeit wiesen noch eine mittelalterliche Struktur auf. Mit einem komplizierten Verfahren und auf Grundlage eines noch meist mündlich tradierten Gewohnheitsrechts fällten die Gerichte ihre Urteile. Ein regelrechter Verfahrensgang zwischen den einzelnen Institutionen hatte sich hierbei noch nicht ausgeprägt, vielmehr bestanden häufig verschiedene $\mathrm{Ge}-$ richte nebeneinander. Während die Institutionen schon in ihrer Bezeichnung, aber auch in ihren Zuständigkeiten stark an die des übrigen Nordfrankreich erinnern, wird die Zugehörigkeit zum Reich lediglich bei der Berufungsmöglichkeit vor dem Reichskammergericht sowie dem Fehlen einer solchen Berufungsmöglichkeit in Strafsachen deutlich. Die königliche Rechtspolitik traf hier also nicht auf ein völlig verschiedenartiges System der Gerichtsorganisation und Rechtsprechung, sondern auf ein durchaus verwandtes, das jedoch in vielem noch seine mittelalterlichen Züge bewahrt hatte.

${ }^{147}$ Vgl. dazu v.a. Eugène MARTIN, L'université de Pont-à-Mousson 1572-1768, Paris, Nancy 1891, S. 15-16, 34-66. Entsprechend fand die Universität schon bald regen Zulauf und zählte im Jahr 1606 uber 2000 Studenten. Die Studentenzahlen bei CABOURDIN, Histoire, Bd. 3,1, S. 114. 